\title{
The Prognositic Significance of Serial Renal Function Measurements in Chronic Heart Failure
}

Takamasa Sato*, Hiroyuki Yamauchi, Satoshi Suzuki, Akiomi Yoshihisa, Takayoshi Yamaki, Koichi Sugimoto, Hiroyuki Kunii, Kazuhiko Nakazato, Shu-ichi Saitoh and Yasuchika Takeishi

Department of Cardiology and Hematology, Fukushima Medical University, Japan

*Corresponding author: Takamasa Sato, Department of Cardiology and Hematology, Fukushima Medical University, 1 Hikarigaoka, Fukushima, 960-1295, Japan, Tel: 8124547-1188, Fax: 8124548-1821; E-mail: takamasa@cap.ocn.ne.jp

Received date: Mar 17, 2014, Accepted date: Apr 21, 2014, Published date: Apr 26, 2014

Copyright: ( 2014 Sato T, et al. This is an open-access article distributed under the terms of the Creative Commons Attribution License, which permits unrestricted use, distribution, and reproduction in any medium, provided the original author and source are credited.

\begin{abstract}
Background: Impaired renal function is a strong prognostic factor in Chronic Heart Failure (CHF). Most studies of it, however, have assessed single measurements of renal function. Thus, the purpose of the present study was to determine the prognostic significance and importance of serial measurements of renal function before and after hospital discharge.

Methods and results: A total of 542 consecutive patients admitted for worsening CHF (455 males, $60.6 \pm 14.2$ years) were studied. Estimated glomerular filtration rate (eGFR) was evaluated before discharge and 6 months later. Patients were followed-up to register cardiac death and rehospitalization due to worsening heart failure. We divided study subjects into four groups based on changes in renal function between before discharge and 6 months after. These were Group 1: normal to normal eGFR ( $\left.\geq 60 \mathrm{~mL} / \mathrm{min} / 17.3 \mathrm{~m}^{2}\right)$, Group 2: reduced $\left(<60 \mathrm{~mL} / \mathrm{min}^{2} 17.3 \mathrm{~m}^{2}\right)$ to normal eGFR, Group 3: normal to reduced eGFR, and Group 4: reduced to reduced eGFR. Compared to Group 1, Groups 2, 3 and 4 had relative risks of 2.265-fold $(P<0.05), 4.055$-fold $(P<0.001)$ and 3.974-fold (P<0.001), respectively, for adverse cardiac events after discharge. The multivariate Cox proportional hazard regression

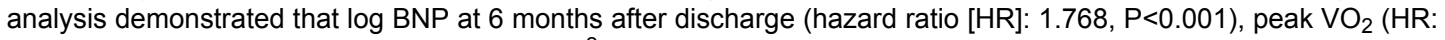
$0.859, \mathrm{P}<0.001)$ and eGFR $<60 \mathrm{~mL} / \mathrm{min} / 1.73 \mathrm{~m}^{2}$ at 6 months (HR: $\left.1.854, \mathrm{P}<0.05\right)$, but not eGFR at discharge, were independent predictors for cardiac events.
\end{abstract}

Conclusion: Changes in renal function by serial measurements after discharge are important for the assessment of risk in $\mathrm{CHF}$.

Keywords: Clinical outcome; Renal function; Chronic heart failure

\section{Introduction}

Many factors, including cardiac functional parameters, exercise capacity, pulmonary function, biomarkers from blood samples, and other clinical characteristics, have determined the prognosis of patients with chronic heart failure (CHF) [1]. One of the strongest prognostic factors of $\mathrm{CHF}$ is impaired renal function [2]. Mortality worsened incrementally across the range of a renal function measurement with a $7 \%$ increased risk for every $10 \mathrm{ml} / \mathrm{min}$ decrease in estimated glomerular filtration rate (eGFR) [3]. It has recently been reported that worsening renal function (WRF) during hospitalization for heart failure is an independent predictor of early readmission and mortality in patients with reduced and preserved systolic function $[4,5]$. However, the clinical impact of WRF after discharge has not been rigorously examined in CHF.

The concept of cardio-renal syndrome and the importance of cardio-renal interaction have been widely accepted [6]. Ronco, et al. presented a classification of the cardio-renal syndrome with subtypes that reflect the pathophysiology, time-frame, and nature of concomitant cardiac and renal dysfunction. Pathophysiological interaction between the heart and kidney in type 2 cardio-renal syndrome or "chronic cardio-renal syndrome" causes progressive chronic kidney disease (CKD) [7].
The purpose of this study was to determine the prognostic significance and importance of taking serial measurements of renal function before and after discharge in patients admitted for the treatment of worsening CHF.

\section{Methods}

\section{Subjects and study protocol}

We examined 542 consecutive patients admitted to Fukushima Medical University Hospital for treatment of worsening CHF between July 2006 and May 2011. Written informed consent was obtained from all study subjects. Our study complies with the Declaration of Helsinki, and the study protocol was approved by the ethical committee of Fukushima Medical University. We diagnosed CHF based on the Framingham criteria, including symptoms, physical examinations, chest $\mathrm{x}$-ray, and echocardiographic findings. All patients received optimal medications and were in stable condition before discharge. They also underwent cardiopulmonary exercise testing (CPX) and echocardiography before discharge. Blood samples were obtained at CPX testing. Exclusion criteria of the present study were decompensated heart failure after treatment, end stage renal disease (eGFR $<15 \mathrm{~mL} / \mathrm{min} / 1.73 \mathrm{~m}^{2}$ ) and malignant diseases. There were 455 males and 87 females; the mean age was $60.6 \pm 14.2$ years. 
Baseline clinical characteristics of the study subjects are shown in Table 1.

\begin{tabular}{|c|c|}
\hline & Total $n=542$ \\
\hline Age (y.o) & $60.6 \pm 14.2$ \\
\hline Male, n (\%) & $455(83.9 \%)$ \\
\hline $\mathrm{BMI}\left(\mathrm{kg} / \mathrm{m}^{2}\right)$ & $23.4 \pm 4.1$ \\
\hline Ischemic etiology, n (\%) & $219(40.4 \%)$ \\
\hline $\mathrm{AF}, \mathrm{n}(\%)$ & $125(23.1 \%)$ \\
\hline $\mathrm{Hb}(\mathrm{g} / \mathrm{dL})$ & $12.9 \pm 1.9$ \\
\hline BUN (mg/dL) & $20.0 \pm 9.7$ \\
\hline creatinine $(\mathrm{mg} / \mathrm{dL})$ & $1.03 \pm 0.39$ \\
\hline eGFR $\left(\mathrm{mL} / \mathrm{min} / 1.73 \mathrm{~m}^{2}\right)$ & $62.9 \pm 20.9$ \\
\hline eGFR at 6 months $\left(\mathrm{mL} / \mathrm{min} / 1.73 \mathrm{~m}^{2}\right)$ & $61.5 \pm 21.6$ \\
\hline $\mathrm{Na}(\mathrm{mEq} / \mathrm{L})$ & $139.8 \pm 2.9$ \\
\hline $\mathrm{UA}(\mathrm{mg} / \mathrm{dL})$ & $6.52 \pm 1.77$ \\
\hline T.Bil (mg/dL) & $0.85 \pm 0.50$ \\
\hline Log BNP & $4.78 \pm 1.25$ \\
\hline Log BNP at 6 months & $4.50 \pm 1.36$ \\
\hline $\operatorname{LVEF}(\%)$ & $44.9 \pm 14.7$ \\
\hline LVEDV (mL) & $126.2 \pm 63.5$ \\
\hline LVESV (mL) & $75.1 \pm 55.2$ \\
\hline $\mathrm{LAD}(\mathrm{mm})$ & $43.3 \pm 9.5$ \\
\hline DcT (msec) & $205.5 \pm 71.9$ \\
\hline$E^{\prime}(m / s)$ & $0.071 \pm 0.028$ \\
\hline E/E' ratio & $12.2 \pm 6.55$ \\
\hline Peak VO $2(\mathrm{~mL} / \mathrm{kg} / \mathrm{min})$ & $16.1 \pm 5.0$ \\
\hline Peak HR (bpm) & $119.3 \pm 28.4$ \\
\hline $\mathrm{VE} / \mathrm{VCO}_{2}$ slope & $32.9 \pm 7.0$ \\
\hline \multicolumn{2}{|l|}{ Pharmacotherapy } \\
\hline Digitalis, n (\%) & $56(10.3 \%)$ \\
\hline ACE inhibitor or ARB, $n(\%)$ & $484(89.3 \%)$ \\
\hline Beta-blocker, n (\%) & $478(88.2 \%)$ \\
\hline Statin, $n(\%)$ & $250(46.1 \%)$ \\
\hline Aldosterone antagonist, $\mathrm{n}(\%)$ & $280(51.7 \%)$ \\
\hline Diuretics, n (\%) & $333(61.4 \%)$ \\
\hline
\end{tabular}

Table 1: Clinical characteristics of study subjects.

$\mathrm{BMI}$, body mass index; $\mathrm{AF}$, atrial fibrillation; $\mathrm{Hb}$, hemoglobin; BUN, blood nitrogen urea; eGFR, estimated glomerular filtration rate; $\mathrm{Na}$, sodium; T.Bil, total bilirubin; BNP, B-type natriuretic peptide;
LVEF, left ventricular ejection fraction; LVEDV, left ventricular enddiastolic volume; LVESV, left ventricular end-systolic volume; LAD, left atrial dimension; DcT, deceleration time; E/E', ratio of mitral peak velocity of early filling (E) to early diastolic annular mitral velocity (E'); Peak $\mathrm{VO}_{2}$, peak oxygen uptake; peak $\mathrm{HR}$, peak heart rate; $\mathrm{VE} / \mathrm{VCO}_{2}$ slope, rate of increase in ventilation per unit increase in carbon dioxide production; ACE, angiotensin-converting enzyme; $\mathrm{ARB}$, angiotensin-receptor blocker; CCB, calcium channel blocker.

Patients in this study were followed up to 6 months after discharge to register cardiac events. The endpoints were cardiac death and rehospitalization due to worsening heart failure. The follow-up period was $523 \pm 303$ days (mean \pm SD) and was completed for all patients. Events were adjudicated using medical records, death certificates, and a questionnaire method for home doctors.

Blood samples were obtained and renal function was measured at 6 months after discharge. Estimated GFR was defined by the Modification of Diet in Renal Disease (MDRD) equation in Japan (recommendation of Japanese Society of Nephrology) [8]. The adjusted hazard ratio for cardiovascular events also increased inversely with the estimated GFR $<60 \mathrm{~mL} / \mathrm{min} / \mathrm{m}^{2}$ [9]. Thus, we defined the lower limit of eGFR as $60 \mathrm{~mL} / \mathrm{min} / 1.73 \mathrm{~m}^{2}$, and divided the patients into 4 groups by changes in eGFR from baseline to 6 months after discharge (Group 1 was normal to normal eGFR; Group 2 was reduced to normal eGFR: Group 3 was normal to reduced eGFR; and Group 4 was reduced to reduced eGFR).

\section{Cardiopulmonary exercise testing}

All subjects performed incremental symptom-limited exercise testing using an upright cycle ergometer with a ramp protocol (Strength Ergo 8, Fukudadenshi Co. Ltd., Tokyo, Japan). Breath by breath oxygen consumption $\left(\mathrm{VO}_{2}\right)$, carbon dioxide production $\left(\mathrm{VCO}_{2}\right)$ and minute ventilation (VE) were measured during exercise using an Aeromonitor AE-300S (Minato Medical Science, Osaka, Japan). Peak $\mathrm{VO}_{2}$ was measured as an average of the last 30 seconds of exercise. Ventilatory response to exercise (expressed as a $\mathrm{VE} / \mathrm{VCO}_{2}$ slope) was calculated as the regression slope relating $\mathrm{VE}$ to $\mathrm{CO}_{2}$ from the start of exercise until the respiratory compensation (RC) point (the time at which ventilation is stimulated by $\mathrm{CO}_{2}$ output and end-tidal $\mathrm{CO}_{2}$ tension begins to decrease) $[10,11]$.

\section{Echocardiography}

Left ventricular end-diastolic and end-systolic volumes (LVEDV and LVESV), and left ventricular ejection fraction (LVEF) were measured by the modified Simpson's method. Standard measurements of left atrial diameter (LAD) were also obtained in the parasternal long axis view [12]. Pulsed-wave Doppler recordings of the mitral flow velocity at the tip of the mitral leaflets were obtained from apical 4 chamber view during quiet respiration. From the Doppler profile, peak velocities of the early (E) wave and late (A) wave were calculated, together with the deceleration time of the $\mathrm{E}$ wave (DcT), taken as the time interval between the peak $\mathrm{E}$ wave and the zero intercept of the deceleration profile's slope [13]. From tissue-Doppler imaging, the mitral annulus velocity (E') was measured, and the ratio of peak $\mathrm{E}$ wave velocity to E' wave velocity (E/E') was accepted for analysis.

\section{Statistical analysis}

Results are presented as mean \pm SD for continuous variables and as numbers and percentages for categorical variables. The Student's $t$-test 
Page 3 of 6

was used to compare continuous variables. If data were not distributed normally, the Mann-Whitney $U$ test was used. The Chi-square test was used to compare categorical variables. A $\mathrm{P}$ value $<0.05$ was considered statistically significant. The Cox proportional hazard regression model was used to determine which variables were associated with cardiac events. We entered the variables including body mass index (BMI), blood urea nitrogen (BUN), eGFR (at discharge and at 6 months after discharge), sodium concentration $(\mathrm{Na})$, hemoglobin $(\mathrm{Hb})$, uric acid (UA), log B-type natriuretic peptide (BNP, at discharge and at 6 months later), LVEF, LAD, DcT, E/E', Peak $\mathrm{VO}_{2}$, and $\mathrm{VE} / \mathrm{VCO}_{2}$, and adjusted for age and gender. Significant variables selected in the univariable analysis were entered into the multivariable analysis. The cardiac event-free rates were calculated using the Kaplan-Meier analysis, and the log-rank test was used to compare the results. All statistical analyses were performed using SPSS statistics version 21.0 (SPSS Inc., Chicago, IL).

\section{Results}

\section{Clinical characteristics of the study subjects}

Clinical characteristics of the study subjects are shown in Table 1. Patients were relatively young with an average age of 60.6 years; $83.9 \%$ were male, $40.4 \%$ had ischemic etiology, and $23.1 \%$ had atrial fibrillation. Most subjects were prescribed pharmacotherapy based on the evidence of their disease. Laboratory data, echocardiographic findings and CPX data are shown in Table 1. The average left ventricular ejection fraction was $44.9 \%$, and exercise capacity was relatively preserved.

\section{Comparison of clinical characteristics and functional data between patients with and without cardiac events in $\mathrm{CHF}$}

During the follow-up period ( $523 \pm 303$ days), a total of 131 cardiac events were registered, including 22 cardiac deaths and 109 rehospitalizations due to worsening heart failure. Table 2 shows comparisons of clinical characteristics, laboratory data, echocardiographic findings, CPX data and medications between patients with and without cardiac events. Patients with cardiac events were older and were associated with higher frequencies of atrial fibrillation than those without cardiac events. In the cardiac events group, BMI was significantly lower than in those with non-cardiac events. Patients with cardiac events had lower hemoglobin concentrations, higher concentrations of BUN, creatinine and UA, lower eGFR (at discharge and after 6 months), lower $\mathrm{Na}$ and higher plasma BNP levels (at discharge and after 6 months) than those without such events. There was no significant change of eGFR between those at discharge and at 6 months later in patients without cardiac events $\left(65.7 \mathrm{~mL} / \mathrm{min} / 1.73 \mathrm{~m}^{2} \mathrm{VS} 65.3 \mathrm{~mL} / \mathrm{min} / 1.73 \mathrm{~m}^{2}\right)$, but in patients with cardiac events, eGFR further reduced from discharge to 6 months $\left(54.2 \mathrm{~mL} / \mathrm{min} / 1.73 \mathrm{~m}^{2}\right.$ vs. $\left.49.6 \mathrm{~mL} / \mathrm{min} / 1.73 \mathrm{~m}^{2}, \mathrm{P}<0.001\right)$. In patients without cardiac events, log BNP further reduced from discharge to 6 months later $(4.79 \mathrm{pg} / \mathrm{mL}$ vs. $4.51 \mathrm{pg} / \mathrm{mL}, \mathrm{P}<0.001$ and $4.48 \mathrm{pg} / \mathrm{mL}$ vs. $4.11 \mathrm{pg} / \mathrm{mL}, \mathrm{P}<0.001$, respectively). However, there was no significant change in log BNP between those at discharge and at 6 months later in patients with cardiac events $(5.70 \mathrm{pg} / \mathrm{ml}$ vs. $5.69 \mathrm{pg} / \mathrm{mL})$. Patients with cardiac events had a lower LVEF, larger LV volume, larger LAD, shorter DcT, and a higher ratio of E/E' compared to those without cardiac events. Furthermore, patients with cardiac events had lower peak $\mathrm{VO}_{2}$, lower peak heart rate, and a higher $\mathrm{VE} / \mathrm{VCO}_{2}$ slope than those without cardiac events, and were prescribed more intensive pharmacotherapy based on evidence.

\begin{tabular}{|c|c|c|c|}
\hline & $\begin{array}{ll}\text { event } & (-) \\
\mathrm{n}=411\end{array}$ & $\begin{array}{l}\text { event } \\
n=131\end{array}$ & $P$ value \\
\hline Age (y.o) & $59.8 \pm 14.4$ & $63.0 \pm 13.6$ & $<0.05$ \\
\hline Male, n (\%) & $111(84.7 \%)$ & $344(83.7 \%)$ & n.s \\
\hline BMI $\left(\mathrm{kg} / \mathrm{m}^{2}\right)$ & $23.6 \pm 3.9$ & $22.6 \pm 4.6$ & $<0.05$ \\
\hline Ischemic etiology, n (\%) & $178(43.3 \%)$ & $51(38.9 \%)$ & n.s \\
\hline $\mathrm{AF}, \mathrm{n}(\%)$ & $73(17.8 \%)$ & $52(39.7 \%)$ & $<0.001$ \\
\hline $\mathrm{Hb}(\mathrm{g} / \mathrm{dL})$ & $13.2 \pm 1.8$ & $12.2 \pm 1.9$ & $<0.001$ \\
\hline BUN (mg/dL) & $18.4 \pm 8.4$ & $24.9 \pm 11.6$ & $<0.001$ \\
\hline creatinine (mg/dL) & $0.98 \pm 0.36$ & $1.19 \pm 0.43$ & $<0.001$ \\
\hline eGFR $\left(\mathrm{mL} / \mathrm{min} / 1.73 \mathrm{~m}^{2}\right)$ & $65.7 \pm 20.3$ & $54.2 \pm 20.4$ & $<0.001$ \\
\hline \multicolumn{4}{|l|}{ eGFR } \\
\hline at 6 months $\left(\mathrm{mL} / \mathrm{min} / 1.73 \mathrm{~m}^{2}\right)$ & $65.3 \pm 20.9$ & $49.6 \pm 19.4$ & $<0.001$ \\
\hline $\mathrm{Na}(\mathrm{mEq} / \mathrm{L})$ & $140.2 \pm 2.6$ & $138.4 \pm 3.2$ & $<0.001$ \\
\hline $\mathrm{UA}(\mathrm{mg} / \mathrm{dL})$ & $6.36 \pm 1.62$ & $7.05 \pm 2.10$ & $<0.001$ \\
\hline T.Bil (mg/dL) & $0.86 \pm 0.50$ & $0.84 \pm 0.50$ & n.s \\
\hline Log BNP & $4.48 \pm 1.21$ & $5.70 \pm 0.91$ & $<0.001$ \\
\hline Log BNP at 6 months & $4.10 \pm 1.23$ & $5.69 \pm 0.99$ & $<0.001$ \\
\hline LVEF (\%) & $47.4 \pm 14.4$ & $37.0 \pm 12.9$ & $<0.01$ \\
\hline LVEDV (mL) & $117.0 \pm 53.8$ & $155.9 \pm 80.4$ & $<0.01$ \\
\hline LVESV (mL) & $65.7 \pm 45.4$ & $104.5 \pm 70.8$ & $<0.001$ \\
\hline LAD (mm) & $41.8 \pm 8.9$ & $48.0 \pm 9.9$ & $<0.001$ \\
\hline DcT (msec) & $211.1 \pm 71.3$ & $186.8 \pm 70.8$ & n.s \\
\hline$E^{\prime}(m / s)$ & $0.071 \pm 0.028$ & $0.070 \pm 0.027$ & n.s \\
\hline E/E' ratio & $11.8 \pm 6.5$ & $13.4 \pm 6.5$ & $<0.05$ \\
\hline Peak VO $2(\mathrm{~mL} / \mathrm{kg} / \mathrm{min})$ & $17.3 \pm 4.9$ & $12.2 \pm 3.2$ & $<0.001$ \\
\hline Peak HR (bpm) & $123.5 \pm 29.1$ & $106.7 \pm 21.4$ & $<0.001$ \\
\hline $\mathrm{VE} / \mathrm{VCO}_{2}$ slope & $31.6 \pm 6.1$ & $37.3 \pm 8.0$ & $<0.001$ \\
\hline \multicolumn{4}{|l|}{ Pharmacotherapy } \\
\hline Digitalis, n (\%) & $30(7.3 \%)$ & $26(19.8 \%)$ & $<0.001$ \\
\hline ACE inhibitor or ARB, $n(\%)$ & $359(87.3 \%)$ & $125(95.4 \%)$ & $<0.05$ \\
\hline Beta-blocker, n (\%) & $351(85.4 \%)$ & $127(96.9 \%)$ & $<0.001$ \\
\hline Statin, n (\%) & $205(49.9 \%)$ & $45(34.4 \%)$ & $<0.05$ \\
\hline Aldosterone antagonist, $\mathrm{n}(\%)$ & $182(44.3 \%)$ & $98(74.8 \%)$ & $<0.001$ \\
\hline Diuretics, n (\%) & $215(52.3 \%)$ & $118(90.1 \%)$ & $<0.001$ \\
\hline
\end{tabular}

Table 2: Comparisons of patients with or without cardiac events. 
Page 4 of 6

\section{Prognostic factors for cardiac events in study subjects}

The ability to predict cardiac events with variables in this study was examined by the univariate and multivariate Cox proportional hazard analyses (Table 3 ). The univariate analysis revealed the significant association of BMI, BUN, eGFR (at discharge and after 6 months), Na, hemoglobin, log BNP (at discharge and after 6 months), LVEF, LAD, $\mathrm{DcT}, \mathrm{E} / \mathrm{E}$ ' peak $\mathrm{VO}_{2}$, and the $\mathrm{VE} / \mathrm{VCO}_{2}$ slope with cardiac events among all variables, as analyzed in Table 3 . The variables with $\mathrm{P}$ values of less than 0.05 by the univariate analysis were entered into the multivariate Cox proportional hazard regression model. Multivariate Cox hazard analysis demonstrated that log BNP (hazard ratio [HR]: $1.768,95 \%$ confidence interval $[\mathrm{CI}]: 1.404-2.227, \mathrm{P}<0.001)$, peak $\mathrm{VO}_{2}$ (HR: $0.859,95 \%$ CI: $0.797-0.926, \mathrm{P}<0.001$ ), and $e G F R<60 \mathrm{~mL} / \mathrm{min} /$ $1.73 \mathrm{~m}^{2}$ at 6 months (HR: $1805,95 \%$ CI: $1.032-3.155, \mathrm{P}<0.05$ ), but not eGFR at discharge, were independent factors to predict adverse clinical outcomes.

\begin{tabular}{|c|c|c|c|c|c|c|}
\hline & \multicolumn{3}{|c|}{ Univariable } & \multicolumn{3}{|c|}{ Multivariable } \\
\hline & $\mathrm{HR}$ & $95 \% \mathrm{Cl}$ & $P$ value & $\mathrm{HR}$ & $95 \% \mathrm{Cl}$ & $P$ value \\
\hline BMI & 0.939 & $0.896-0.984$ & $<0.01$ & 0.971 & $0.925-1.020$ & n.s \\
\hline $\mathrm{Hb}$ & 0.768 & $0.699-0.844$ & $<0.001$ & 0.935 & $0.827-1.058$ & n.s \\
\hline BUN & 1.043 & $1.032-1.055$ & $<0.01$ & 1.003 & $0.980-1.026$ & n.s \\
\hline eGFR at discharge $<60 \mathrm{~mL} / \mathrm{min} / 1.73 \mathrm{~m}^{2}$ & 2.429 & $1.693-3.484$ & $<0.001$ & 1.060 & $0.612-1.835$ & n.s \\
\hline eGFR at 6 months $<60 \mathrm{~mL} / \mathrm{min} / 1.73 \mathrm{~m}^{2}$ & 1.832 & $1.509-2.224$ & $<0.001$ & 1.805 & $1.032-3.155$ & $<0.05$ \\
\hline $\mathrm{Na}$ & 0.835 & $0.794-0.879$ & $<0.001$ & 1.000 & $0.935-1.069$ & n.s \\
\hline UA & 1.213 & $1.103-1.334$ & $<0.01$ & 1.016 & $0.907-1.138$ & n.s \\
\hline Log BNP at discharge & 2.051 & $2.090-2.993$ & $<0.001$ & 1.211 & $0.912-1.609$ & n.s \\
\hline $\begin{array}{l}\text { Log BNP } \\
\text { at } 6 \text { months }\end{array}$ & 2.447 & $2.135-2.873$ & $<0.001$ & 1.768 & $1.404-2.227$ & $<0.001$ \\
\hline LVEF & 0.960 & $0.949-0.972$ & $<0.01$ & 0.989 & $0.974-1.004$ & n.s \\
\hline LAD & 1.057 & $1.040-1.073$ & $<0.01$ & 1.018 & $0.994-1.044$ & n.s \\
\hline DCT & 0.995 & $0.992-0.998$ & $<0.01$ & 0.999 & $0.996-1.002$ & n.s \\
\hline Peak $\mathrm{VO}_{2}$ & 0.750 & $0.710-0.793$ & $<0.001$ & 0.859 & $0.797-0.926$ & $<0.001$ \\
\hline $\mathrm{VE} / \mathrm{VCO}_{2}$ slope & 1.089 & $1.068-1.110$ & $<0.001$ & 0.994 & $0.964-1.025$ & n.s \\
\hline
\end{tabular}

Table 3: Cox proportional hazard analyses to predict cardiac events.

\section{Risk prediction of changes in eGFR}

Table 4 shows the hazard ratios of each group calculated based on a comparison to Group 1 by Cox proportional model. Reduced to normal eGFR (Group 2) carried a 2.265-fold increase in risk for cardiac events. Reduced to reduced eGFR (Group 4) carried a 3.974fold increase in risk for cardiac events. Normal to reduced eGFR (Group 3) carried a 4.055-fold increase in risk for cardiac events. In addition, Kaplan Meier analysis revealed that the time-dependent cardiac event rates in Groups 3 and 4 were significantly higher than those in Groups 1 and 2 (Figure 1).

\section{Discussion}

In the present study, WRF during clinical follow-up in patients with CHF was highly associated with the increased risk of adverse cardiac events. Cox proportional hazard regression analysis demonstrated that eGFR $<60 \mathrm{~mL} / \mathrm{min} / 1.73 \mathrm{~m}^{2}$ at 6 months was an independent predictor of cardiac events, as well as log BNP at 6 months and peak $\mathrm{VO}_{2}$, but not eGFR at baseline (discharge). Continuous follow-up of renal function provided us useful information for risk assessment.

\section{CKD and CHF}

It is now widely accepted that CHF is characterized by activation of the renin-angiotensin-aldosterone system, sympathetic nervous system, inflammation, oxidative stress, and etc [2]. Recent studies have demonstrated that CKD increases the risk of cardiovascular events [9]. In $\mathrm{CHF}$, high incidence of renal dysfunction has been reported, and impaired renal function is a strong predictor of mortality $[14,15]$. However, most studies have measured CHF as a single measurement. In our study, renal function was a strong factor for predicting adverse cardiac events in CHF.

\section{Worsening renal function in CHF}

WRF during hospitalization for heart failure is an independent predictor of early readmission and mortality in patients with reduced and preserved systolic function [4,5]. On the other hand, renal dysfunction on admission was one of the more important factors to predicting clinical outcomes than WRF during hospitalization [16]. However, the clinical significance of WRF during hospitalization is still controversial and should be re-evaluated [17]. WRF alone, when detected using serial serum creatinine measurements, is not an 
independent determinant of outcomes in patients with acute decompensated heart failure. One possible reason for this is that WRF in acute decompensated heart failure is affected by congestion, hypoxia, use of diuretics and renin-angiotensin- aldosterone inhibitors [18]. We demonstrated here that eGFR at 6 months, but not eGFR at discharge, was an independent prognostic factor in CHF (Table 3). Furthermore, we clearly showed that WRF at 6 months was associated with adverse clinical outcomes (Table 4 and Figure 1).

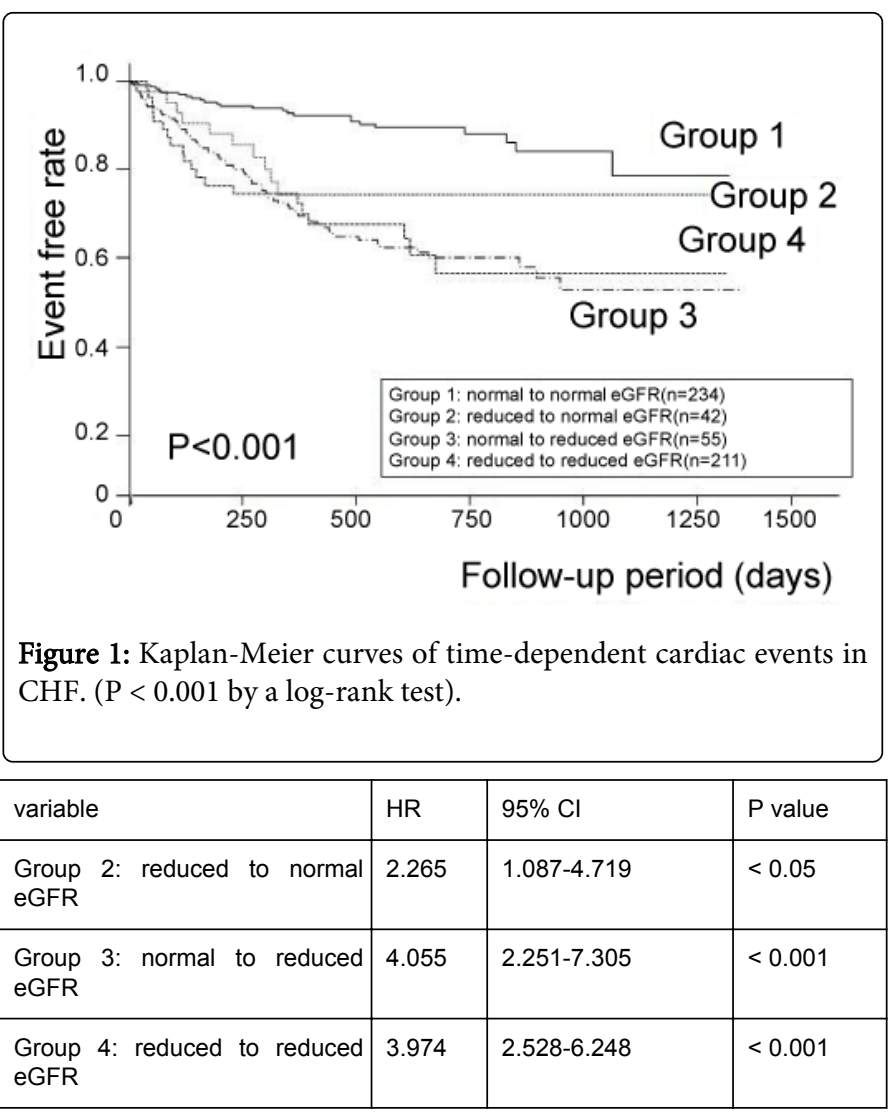

Table 4: Effect of change from baseline in eGFR at 6 months on outcome of cardiac events Relative to Group 1.

\section{Serial measurement of BNP}

Log BNP at 6 months was an independent prognostic factor in this study. In addition, we divided study subjects into 2 groups according to the median value of delta BNP (BNP level at 6 months - BNP level at discharge). There was no difference in the cardiac event rate between the two groups by Kaplan-Meier analysis (log lank $\mathrm{P}=0.094)$. In CHF patients at 6 months after hospital discharge for decompensated HF, BNP was the strongest factor for predicting readmission due to heart failure [19]. In the ESC guideline, several randomized clinical trials that evaluated natriuretic peptide-guided treatment (intensifying treatment in order to lower peptide levels) have given conflicting results. It is uncertain whether the outcome would be better using this approach than by simply optimizing treatment (combinations and doses of drugs and devices) according to guidelines [20]. On the other hand, the ACCF/AHA guideline demonstrated through 2 comprehensive meta-analyses that BNPguided therapy reduces all-cause mortality in patients with chronic HF compared with usual clinical care, especially in patients $<75$ years of age. This survival benefit may be attributed to the increased benefits from guideline-directed medical therapy [21].

\section{Relations between BNP and eGFR}

There was a significant correlation between plasma BNP levels and eGFR in this study. However, we examined changed BNP values obtained by serial measurements between CHF patients with normalto-normal and normal-to-reduced eGFR. There were no significant differences between the two groups. It has been previously reported that decreased clearance from the kidney contributes to elevated plasma BNP in CHF patients with renal dysfunction. In addition, regarding the plasma level of $\mathrm{BNP}$, left ventricular ejection fraction and left ventricular end-diastolic pressure and eGFR were independent predictors [22]. However, eGFR is an independent predictor of adverse cardiac events even after adjustment for the other covariates, including BNP [23]. The effect of renal dysfunction is not only co-morbidity of cardiac dysfunction, but also an independent risk of CHF.

\section{Study limitations}

Since severe CHF patients who could not perform exercise testing and those with end stage renal disease were excluded from the present study, our observations may not fully apply to patients with more advanced $\mathrm{CHF}$ and more severely-impaired renal function.

Medical treatment including ACE inhibitors, ARBs, mineralcorticoid antagonists and diuretics changes affected eGFR changes in follow-up. However, we were unable to check medical treatment changes. We should consider this in future studies. Non-cardiac death and hospitalization were important in CHF. Although, we did not check these events in this study, we will examine them in the future studies.

\section{Conclusions}

Progressive renal dysfunction after discharge was an important factor for predicting unfavorable clinical outcomes in CHF. Thus, changes in renal function should be considered by serial measurements.

\section{References}

1. Greenberg B, Kahn AM (2011) Clinical aspects in heart failure. In: Bonow RO, Mann DL, Zipes DP, Libby P, eds. Prognosis in Braunwald's Heart Disease (7th edn). Elsevier Saunders, Pennsylvania 505-516.

2. Hillege HL, Girbes AR, de Kam PJ, Boomsma F, de Zeeuw D, et al. (2000) Renal function, neurohormonal activation, and survival in patients with chronic heart failure. Circulation 102: 203-210.

3. Smith GL, Lichtman JH, Bracken MB, Shlipak MG, Phillips CO, et al. (2006) Renal impairment and outcomes in heart failure: systematic review and meta-analysis. J Am Coll Cardiol 47: 1987-1996.

4. Klein L, Massie BM, Leimberger JD, O'Connor CM, Piña IL, et al. (2008) Admission or changes in renal function during hospitalization for worsening heart failure predict postdischarge survival: results from the Outcomes of a Prospective Trial of Intravenous Milrinone for Exacerbations of Chronic Heart Failure (OPTIME-CHF). Circ Heart Fail 1: 25-33.

5. Patel UD, Greiner MA, Fonarow GC, Phatak H, Hernandez AF, et al. (2010) Associations between worsening renal function and 30-day outcomes among Medicare beneficiaries hospitalized with heart failure. Am Heart J 160: 132-138.

6. Bock JS, Gottlieb SS (2010) Cardiorenal syndrome: new perspectives. Circulation 121: 2592-2600. 
Citation: Sato T, Yamauchi H, Suzuki S, Yoshihisa A, Yamaki T et al. (2014) The Prognositic Significance of Serial Renal Function Measurements in Chronic Heart Failure. J Gen Pract 2: 156. doi:10.4172/2329-9126.1000156

Page 6 of 6

7. Ronco C, Haapio M, House AA, Anavekar N, Bellomo R (2008) Cardiorenal syndrome. J Am Coll Cardiol 52: 1527-1539.

8. Sasaki S (2009) Preface: evidence-based practice guideline for the treatment of chronic kidney disease. Clin Exp Nephrol 13: 533.

9. Go AS, Chertow GM, Fan D, McCulloch CE, Hsu CY (2004) Chronic kidney disease and the risks of death, cardiovascular events, and hospitalization. N Engl J Med 351: 1296-1305.

10. Chua TP, Ponikowski P, Harrington D, Anker SD, Webb-Peploe K, et al. (1997) Clinical correlates and prognostic significance of the ventilatory response to exercise in chronic heart failure. J Am Coll Cardiol 29: 1585-1590.

11. Ponikowski P, Francis DP, Piepoli MF, Davies LC, Chua TP, et al. (2001) Enhanced ventilatory response to exercise in patients with chronic heart failure and preserved exercise tolerance: marker of abnormal cardiorespiratory reflex control and predictor of poor prognosis. Circulation 103: 967-972.

12. Lang RM, Bierig M, Devereux RB, Flachskampf FA, Foster E, et al. (2005) Recommendations for chamber quantification: a report from the American Society of Echocardiography's Guidelines and Standards Committee and the Chamber Quantification Writing Group, developed in conjunction with the European Association of Echocardiography, a branch of the European Society of Cardiology. J Am Soc Echocardiogr 18: 1440-1463.

13. Garhard-Herman M, Gardin M, Jaff M, Mohler E, Roman M, et al. (2006) American Society of Echocardiography and the Society of Vascular Medicine and Biology. Guidelines for noninvasive vascular laboratory testing. J Am Soc Echocardiogr 19: 955-972.

14. Hillege HL, Nitsch D, Pfeffer MA, Swedberg K, McMurray JJ, et al. (2006) Renal function as a predictor of outcome in a broad spectrum of patients with heart failure. Circulation 113: 671-678.

15. Ronco C, McCullough P, Anker SD, Anand I, Aspromonte N, et al (2010) Cardio-renal syndromes: report from the consensus conference of the acute dialysis quality initiative. Eur Heart J 31: 703-711.

16. Nohria A, Hasselblad V, Stebbins A, Pauly DF, Fonarow GC, et al. (2008) Cardiorenal interactions: insights from the ESCAPE trial. J Am Coll Cardiol 51: 1268-1274.
17. Blair JE, Pang PS, Schrier RW, Metra M, Traver B, et al. (2011) Changes in renal function during hospitalization and soon after discharge in patients admitted for worsening heart failure in the placebo group of the EVEREST trial. Eur Heart J 32: 2563-2572.

18. Metra M, Davison B, Bettari L, Sun H, Edwards C, et al. (2012) Is worsening renal function an ominous prognostic sign in patients with acute heart failure? The role of congestion and its interaction with renal function. Circulation Heart Fail 5: 54-62.

19. Nishii M, Inomata T, Takehana H, Naruke T, Yanagisawa T, et al. (2008) Prognostic utility of B-type natriuretic peptide assessment in stable lowrisk outpatients with nonischemic cardiomyopathy after decompensated heart failure. J Am Coll Cardiol 51: 2329-2335.

20. McMurray JJ, Adamopoulos S, Anker SD, Auricchio A, Böhm M, et al (2012) ESC guidelines for the diagnosis and treatment of acute and chronic heart failure 2012: The Task Force for the Diagnosis and Treatment of Acute and Chronic Heart Failure 2012 of the European Society of Cardiology. Developed in collaboration with the Heart Failure Association (HFA) of the ESC. Eur Heart J 33: 1787-1847

21. Yancy CW, Jessup M, Bozkurt B, Butler J, Casey DE Jr, et al. (2013) 2013 ACCF/AHA guideline for the management of heart failure: a report of the American College of Cardiology Foundation/American Heart Association Task Force on Practice Guidelines. J Am Coll Cardiol 62: e147-e239.

22. Tsutamoto T, Wada A, Sakai H, Ishikawa C, Tanaka T, et al. (2006) Relationship between renal function and plasma brain natriuretic peptide in patients with heart failure. J Am Coll Cardiol 47: 582-586.

23. Hamaguchi S, Tsuchihashi-Makaya M, Kinugawa S, Yokota T, Ide T, et al. (2009) Chronic kidney disease as an independent risk for long-term adverse outcomes in patients hospitalized with heart failure in Japan. Report from the Japanese Cardiac Registry of Heart Failure in Cardiology (JCARE-CARD). Circ J 73: 1442 - 1447. 